\title{
Patients' Resistance towards Health Information Technology: A Perspective of the Dual Factor Model of IT Usage
}

\author{
Bahae Samhan \\ Illinois State University \\ bmsamha@ilstu.edu
}

\begin{abstract}
This paper presents a research model of patients' resistance towards Health Information Technology (HIT). In particularly it examines patients' reactions towards a new Patient Portal System (PPS). This work provides an integration of the technology acceptance and resistance to change literatures. The Resistance to Change construct from the User Resistance Model (URM), and the Unified Theory of Acceptance and Use of Technology (UTAUT) are bridged using the dual-factor model of technology usage. This model explains the asymmetric effects of use inhibitors such as Resistance to Change on use enablers such as Performance Expectancy and Effort Expectancy. The integrative model is empirically supported using survey data collected from patients of a large public international hospital. Total of 265 valid responses were used for the data analysis. This study highlights the importance of integrating resistance to change with the technology use research especially in healthcare settings that is considered to be under researched. Moreover, it is considered to be one of the first studies in IS that brings in patients' perspectives of new HIT.
\end{abstract}

\section{Introduction}

Technology advancements of today are not only changing the way organizations perform their tasks, but also how individuals perform their daily tasks. Just like how organizations implement information systems to keep operations running smoothly, people are being surrounded with technologies that aim to make their life easier. Generally, technology not only facilitates connectivity, communication, file transferring, and secure storage of data, but also has the potential to decrease the time needed to complete a task, or in some cases eliminate the need for a business process or job function. However, evidence show that the healthcare sectors are still enduring acts of Health Information Technology (HIT) resistance [5, 2, and 30]. HIT resistance is a phenomenon that is prominent within healthcare providers as well as with patients [5]. Like other industries, healthcare organizations became aware of the potential benefits of using different types of HIT such as Electronic Health Records (EHR) and Computerized Physician Order Entry systems (CPOE). Additionally, healthcare organizations are facilitating communications with patients through electronic patient portals. A Patient Portal is a secure online website that gives patients convenient 24-hour access to personal health information from anywhere with an Internet connection. Using a secure username and password, patients can view health information such as: recent doctor visits, lab results, doctors' notes, and in some cases patients can leave their doctors a message about a concern or a question they might have. However, HIT are often strongly resisted by the same potential users that are expected to benefit from its use [2] [5].

User resistance is considered to be the main contributor to system failure [23]. Thus, in this study we aim to investigate why HIT is resisted by its potential users? More specifically, this study focuses on resistance behaviors manifested by patients. Today, patients are considered as major stakeholders in the healthcare process [40]. Patients are being able to interact with a variety of HIT such as medical mobile apps that are widely spread and easily accessed by patients [50]. Also there is a wide spread of diagnostic tools that are available and easily accessed over the web [51]. This study focuses on patients' resistance behaviors towards patient portal systems (PPS).

The literature showed limited work on patients' resistance to HIT [5]. In most of the HIT studies such as [2, 27, and 30] the focus was only on the physicians, nurses, radiologists, lab specialists, pharmacists, or health organizations managers but not the patients. This is a major research gap in the IS literature. Understanding why patients resist the PPS and how such resistance is manifested in their subsequent behavior can help decision makers take appropriate intervention for minimizing resistance behaviors and any subsequent effects. Further, most 
HIT designers normally focus on system considerations, such as connectivity, new functionalities, and security, with limited user considerations such as how intuitive is the system to the average user [2]. Better understanding of patients' resistance towards PPS may help design systems that are acceptable to the average user and still remain functionally good. This work also contributes to the IS research that has very limited work examining patients' behaviors towards HIT. Findings of this work will address this important research gap by enriching the literature with findings from the patients' perspective. This work will examine two main research questions: 1) why do patients resist patient portal systems? And 2) how does resistance influence their usage decision? To address these questions, the underpinnings of the dual factor model of IT usage is adopted [38]. The next section illustrates the theoretical background of this work.

\section{Theoretical Background}

We draw upon the dual factor model of IT usage [38] which suggests that an individual's behaviors towards technologies can be categorized on the basis of enabling factors that encourage the use of the technology and inhibitor factors that discourage the use of the technology. Inhibitors are defined as negative factors that, when present, will discourage technology usage, however the absence of these factors do not necessarily encourage technology usage [38]. Similarly, the presence of positive factors (enablers) will encourage technology usage, but its absence will not necessarily discourage the technology usage. The asymmetric effect of the model implies that inhibitors are not necessarily the opposite of enablers, rather they are distinct constructs that may coexist [2]. Based on the underpinnings of the dual factor model of IT usage, this work proposes that patients' intention to use the PPS is based on both enablers of IT usage, such as perceived usefulness and perceived ease of use [18][45], as well as inhibitors such as user resistance to change [23].

In this work, enablers are represented by PPS usage behaviors, and inhibitors are represented by resistance to change concepts. Patients are introduced to a new way of interacting with healthcare organizations through the newly implemented PPS. The introduction of the new PPS interrupts patients' comfort routine of interacting with their healthcare provider by the traditional ways such as visiting the healthcare organization, or communicating their requests by phone. This implies a major change in patients' environment. Thus, it becomes essential to capture resistance to change behaviors.

While Cenfetelli [38] did not identify any specific inhibitor of IT usage, a prior study [2] suggested that resistance to change fits the classic definition of an inhibitor. It is argued that resistance to change demonstrates asymmetric behaviors typical of inhibitors, because resistance to change may affect usage behaviors but the absence of resistance to change does not necessarily increase usage. Additionally, prior empirical findings such as [32] and [44] confirm that technology use and resistance have different antecedents and are motivated differently, which conforms to the independent nature of enablers and inhibitors of the dual factor model of IT usage.

Prior research has explained resistance to change on basis of "net benefits" as introduced in the Status Quo Bias Theory (SQBT) [47]; and on basis of "net equity" as explained in the Equity Implementation Model (EIM) [27]. The SQBT suggests that resistance behavior is a decision based on the evaluation of the current status of the individual and the perceived future status of the individual after accepting the change. It posits that resistance can be due to the individuals' preference to stay with the current situation. The EIM suggests that resistance to change occurs after the evaluation of increased troubles associated with the change (inputs) versus desired outcomes associated with the change (output). If individuals perceived outputs to be more valuable than associated inputs then the change would be favorable, and vice versa. The work of Kim and Kankanhalli [23] posited the User Resistance Model (URM) which integrates concepts from both EIM and SQBT to explain the outcome variable Resistance to Change. We define resistance to change as "any conduct that serves to maintain the status quo in the face of pressure to alter the status quo" ([19] p. 63).

According to the dual factor model [38], enablers encouraging PPS usage must be identified. However, the URM has limited capabilities in capturing usage behaviors because resistance and use cannot be simply perceived as opposites and must be captured distinctively [2] [30]. Resistance is not equivalent to non-usage and two distinctive models are required to capture both use and resistance constructs. First, use and resistance are distinct behaviors that may coexist simultaneously; for example: procrastination and sabotage behaviors [30]. When users manifest such behaviors, they are in fact resisting the technology without completely eliminating the usage behavior from their interaction with the technology. Second, the technology acceptance theories do not necessarily 
aim to capture the actual antecedents of resistance, but rather explains technology use facilitators. Which makes it difficult to conclude that one is the opposite of the other. Third, non-usage behaviors include those of the individuals who are still evaluating the new technology prior to making an adoption decision, while resistance behaviors conclude that individuals have considered the technology and rejected it [2]. Fourth, resistance is normally coupled with resentment towards the implementation of the new technology. This could be manifested covertly in an aim to delay the implementation of the new technology; whereas non-usage behaviors are not associated with these acts [2]. Fifth, prior work has posited that technology resistance is clearly a barrier to IT usage (e.g. [2], [3], and [30]) which suggests the independency of both constructs. Sixth, Usage behaviors are driven by perceptions related to a specific technology, whereas resistance is a generalized opposition to change rising from the unfavorable expectations associated with the change. Therefore, resistance is not focused so much on a specific technology, rather focuses on the change from the status quo caused by usage [2]. Finally, technology usage can be perceived as a behavior, however resistance is not considered a behavior but rather a cognitive effort preventing a potential behavior [28]. Therefore, resistance is not the mirror opposite of IT acceptance, but a possible antecedent to IT acceptance [2]. This concludes the necessity of capturing PPS usage distinctively. Thus, the Unified Theory of Acceptance and Use of Technology (UTAUT) [45] is used to capture PPS usage behaviors in this study. This work examines both technology use and resistance independently within a common theoretical model based on the dual factor model which bridges both concepts in terms of enablers and inhibitors of PPS usage (see Figure 1). This theoretical model is empirically validated using survey data from patients at a large international public hospital.

\section{Hypotheses}

Social Influence refers to the degree to which a patient perceives that important others believe he or she should use the new PPS [45]. Building on URM, we theorize that patients have the tendency to conform to their important others' opinions because of the need for social companionship and the fear of sanction for noncompliance [24] [46]. So patients' resistance behaviors are directly affected by what other people think about the change to the new PPS. Important others' opinion about the new PPS may alter the original perceptions patients have about the technology. Positive opinions toward the new change can serve to reduce patients' uncertainty and therefore lower their changing resistance. Also, positive opinions about the change to the new PPS would lead to a greater perception of the switching benefits among users, which also results in a having less change resistance. Thus, leading us to the following hypothesis:

H1: Social Influence (positive opinions) about the change to the PPS has a negative effect on patients' Resistance to Change.

Although results in the technology acceptance literature indicates that social influence is significant only in mandatory settings [26], it is suggested that confirmatory behaviors may still occur with voluntary usage. The desire of patients to fit-in among the group of people who are using the PPS may involve a change in their belief or behavior. The work of Kelman [21] distinguished three types of conformity behaviors: Compliance, internalization and identification. Compliance occurs when patients accept influence because they hope to achieve a favorable reaction from others. They adopt the PPS because they expect to gain specific approval and avoid specific disapproval from other PPS users [21]. Internalization occurs when patients accept influence because the content, ideas, and actions of the PPS are consistent with their values [21]. For example, a patient might accept positive influence about the new PPS because he or she already has favorable opinions about other processes that has been digitized such as online banking and emails. Identification occurs when patients accept influence because they want to establish or maintain a satisfying self-defining relationship to other PPS users [21]. This leads us to the following hypothesis.

H2: Social Influence (positive opinions) has a positive effect on patients' Intentions to Use PPS.

While Cenfetelli's dual factor model of IT usage posited that inhibitors can also influence IT usage indirectly through enablers that serve as mediators. This indirect influence is unidirectional, i.e. enablers do not have any corresponding effect on inhibitors [2]. There are three plausible reasons for having these asymmetric effects. First, according to the norm theory [33], individuals' negative perceptions are remembered better, acquire more cognitive attention, and initiates greater information processing than positive ones [12]. Resistance to change acquires greater range of emotional reactions than do enablers [2]. Second, the concepts of loss aversion [11] and risk aversion [10] suggests that people tend to strongly prefer avoiding losses to acquiring gains. 
Thus, negative outcomes would be weighted much more than the positive ones in any given experience. So patients who are resisting the change to PPS would be paying attention to the inhibitors associated with the switch to the PPS more than the enablers. Third, inhibitors tend to generalize individuals' perception of negative experiences which leads to prejudicing all other perceptions, including those of enablers [2]. For example, if a patient experienced an instance of delay, loading error, or system failure of the PPS, this may lead the patient to view the quality of the PPS as poor, despite that the PPS, in more frequent times, was functional and has a number of facilitating capabilities.

The UTAUT has identified four main antecedents to use intentions: Performance Expectancy, Effort Expectancy, Facilitating Conditions, and Social Influence. Performance Expectancy refers to the degree to which patients believes that using the PPS will help them to attain gains in performing their desired tasks [45]. There are five constructs from different models that capture the concept of Performance Expectancy, these are: perceived usefulness [18], extrinsic motivation [45], job-fit [37], relative advantage [20], and outcome expectations [15]. Effort Expectancy refers to the degree of ease associated with the use of the PPS [45]. There are three constructs from different models that capture the concept of Effort Expectancy, these are: perceived ease of use [18], complexity [37], and ease of use [20]. Facilitating Conditions in this study refers to the degree to which a patient believes that the technical infrastructure exists to support the use of the PPS. There are three constructs from different models that capture the concepts of Facilitating Conditions, these are: perceived behavioral control [24] [53] [54], facilitating conditions [37], and compatibility [20]. Social influence in our study is considered as an antecedent to use intentions. However, it was not hypothesized that Resistance to Change will have an effect on social influence for two main reasons. First, being mindful not violate the unidirectional feature of the effects between inhibitors and enablers. The unidirectional effect is concluded by the effect Social Influence on Resistance to Change. Second, the URM suggests that Social Influence has an effect on Resistance to Change. So reversing the direction of the effect will change the original theory and requires further justifications. Third, the Social Influence construct captures others' opinions of the PPS. So by hypothesizing that Resistance to Change has an effect on Social Influence, we are not really testing for the effect of Resistance to Change on the patient himself or his opinions to other, but in fact testing the effect of others' opinions on his own opinion while he is actually resisting the change. This is a counter intuitive argument that cannot be justified within the theory in use.

In summary, the asymmetric effects of inhibitors on enabling perceptions of PPS usage suggest that Resistance to Change will influence enablers in a negative manner. Thus, leading us to the following hypotheses:

H3: Resistance to Change has a negative effect on Performance Expectancy.

H4: Resistance to Change has a negative effect on Effort Expectancy.

H5: Resistance to Change has a negative effect on Facilitating Conditions.

The technology acceptance literature suggest that performance expectancy is a salient cognitive determinant of usage behaviors. Patients will want to use the PPS if they believe it will benefit them by being useful to the task they wish to accomplish. This leads us to the following hypothesis:

H6: Performance Expectancy has a positive effect on patients' Intentions to Use PPS.

Similarly, the technology acceptance literature suggests that effort expectancy is also a cognitive determinants of usage behaviors. Patients will want to use the PPS with minimum effort. Prior empirical work (e.g., [6] [45] [48] [49]) show that Effort Expectancy tend to be positively related to usage intentions. Thus leading us to following hypothesis:

\section{H7: Effort Expectancy has a positive effect on patients' Intentions to Use PPS.}

The UTAUT hypothesized that Facilitating Conditions have no effect on use intentions. This hypothesis was later confirmed by the empirical findings of UTAUT. It is theorized that when performance expectancy constructs and effort expectancy constructs are present together in a model, facilitating conditions becomes nonsignificant in predicting intention [45]. However, we believe that, in this study, the three constructs from the different models that pertain to Facilitating Conditions (i.e. Compatibility, Facilitating Conditions, and Perceived Behavioral Control) will all have positive influence on use intentions. In today's technological era, compatibility is a dealbreaker for technology use. For example, a patient who feels very comfortable using new advanced technological tools may be hesitant to use the new PPS only because the application is not compatible with her phone or tablet. On the other hand, a less IT 
experienced patient may be motivated to use the PPS if the application was compatible with the connecting devices. Additionally, perceived behavioral control to patients from this study means than it does to other populations used in prior studies that found nonsignificant effect between facilitating conditions and use intentions. In this study, patients have full control over every aspect of the interaction with the PPS. They have the freedom to choose the time, location, duration, and device to accomplish the task using the PPS. They even have the freedom to decide whether to use the PPS or not. This ample freedom makes patients react differently to the word "control" in the survey items about the construct. Unlike how general employees respond when asked about the control they have over a mandated technology for work at an organization that expects outcomes to be of a certain quality. Moreover, the facilitating conditions construct posited by [37], which is embedded in the Facilitating Conditions construct of the UTAUT and used in this study, focuses on the support provided to users. This also has different meanings to different populations. For instance, patients do not expect the same support to be available to them when using the PPS as a programmer at a software developing company may expect. If no enough support was available to the patient who wants to view his most recent bill from the hospital, he/she would simply check it later or call the hospital's billing services. Whereas, the programmer will need immediate assistance with the problem in order to complete the project to meet a certain deadline for example. Thus, it is hypothesized in this study that:

H8: Facilitating Conditions has a positive effect on Intentions to Use PPS.

When people are introduced to a new system they often feel a changes in their environment. Because human naturally react to oppose change, and depending on the magnitude of the change, many users will tend to resist the technology which will result in having lower intentions of use [2]. Prior studies such as [16] [42] provided support for the negative effect of resistance on usage. Also, prior work has posited that technology resistance is clearly a barrier to IT usage (e.g., [2] [3] [30]). Moreover, because resistance is a cognitive effort preventing a potential behavior [28]. The potential behavior in this study would be the intentions to use the PPS. This leads us to the following hypothesis:

H9: Patients' Resistance to Change has a negative effect on Intentions to Use PPS.
Finally, in this study we controlled for a number of variables, namely: Age, Sex, and Education Level.

(Figure 1) illustrates the research model of this study on basis of the dual factor model of IT usage [38].

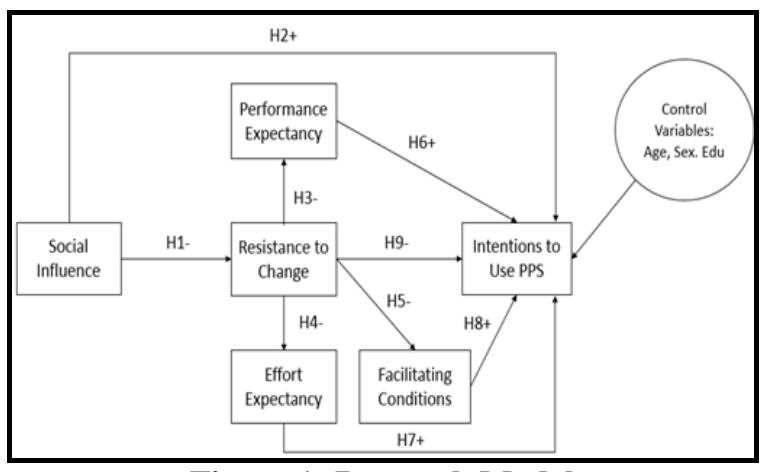

Figure 1: Research Model

\section{Investigative Context}

The technology investigated within this study is a newly implemented patient portal system. The system is available to all patients of a large public hospital located in Amman, Jordan. The PPS is considered to be an informational portal as well as a transactional system. The PPS allows patients to view results of their lab tests, imaging reports, prescriptions, request fill ups for their medicines, schedule and edit appointments, and place follow up questions to their healthcare providers. The system is available as an application that can be installed on most of the portable devices which allows flexibility of access from anywhere at any time. Patients must create an online profile before they are granted access to the system. The online profile includes a secure username and password. The developing company is in the process of launching the latest update of the application to include the option of figure print identification for accessing the application. This will require devices that host the figure print feature. The hospital consists of multiple health departments and 33 specialist clinics. The hospital serves over 400 outpatients every day. The total capacity of the hospital for inpatients is 550 beds, and on average $58 \%$ of these beds are constantly occupied with patients. The patient portal system is an extension of a large Electronic Health Records (EHR) system that was implemented in 2014. The vision of the hospital is to have complete paperless communication with patients in the next 5 years. The PPS was implemented through a governmental program which is the first national e-health initiative in Jordan. The 
system was designed and implemented by Electronic Health Solutions (EHS) which is a non-profit, innovative, technology-driven company established in early 2009. EHS is a partnership between the main healthcare stakeholders: Ministry of Health, Ministry of Information and Communications Technology, Royal Medical Health Awareness Society and Private Hospitals Association. According to EHS, 4.5 million JDs (around \$6.4 million) were invested in specialized resources to develop and implement the entire EHR system and the PPS. The introduction of the PPS brought substantial changes to the process of communication between the patient and the hospital. Patients are gradually switching from using traditional ways of communicating with the hospital to the PPS. Today, $39 \%$ of all patients are registered with the PPS. However, even registered patients may still use traditional ways of communication such as calling, walking in, and requesting printed material. The success of the system is very important to the hospital's stakeholders. Partly because there is no reliable mailing system in Jordan. Thus, patients tend to go to the hospital in person for any request that involves having printed material. This is adding crowd pressure to the hospital's staff that process these requests. Also it raises the concern of having enough physical space at the hospital for all type of visitors (i.e. patients who need medical attention, and patients who only need some paper work such as lab results or medical prescriptions and refills.

\section{Methodology}

\subsection{Instrument Development}

After receiving the exempt notion from the IRB, existing validated scales were adopted for this study. Mainly the instrument items from the URM and UTAUT were used. All items were modified to fit the context of this study. However, there were important edits that were made to the original scales. Measurement items were anchored on five-point Likert scales $(1=$ strongly disagree, $5=$ strongly agree). The instrument was reviewed by IS researchers before the study.

\subsection{Sample and Data Collection}

Data was collected using two methods. First, hard copies (paper based) of the survey were handed out to each patient who walks in to the front desk of the hospital's main building were all of the major circulations take place. Second, a link to the survey was sent to all of the patients who are registered with the PPS. By doing so, we avoid having response bias in this study. Because if the data was collected from only those patients who walk-in, then maybe we will get responses from only patients who do not use the PPS. Similarly, only sending the online survey through the PPS will result in responses only from patients who used the PPS. By integrating both methods we are controlling for any response bias.

Data was collected in two phases: a pilot study and a main study. For the pilot study, data was collected from patients of the dermatology unit at the hospital, a total of 113 responses were collected. After conducting Explanatory Factor Analysis (EFA) and Confirmatory Factor Analysis (CFA) of the data collected for the pilot study, it was necessary to alter some of the items to address a number of issues related to the psychometric properties of factors. Additionally, some new items were added to better capture the concepts of some constructs. After refining the survey items based on the pilot data's psychometric properties, we collected data for the main study from patients of the entire hospital, but patients who filled the first survey (i.e. pilot study) were specifically asked not to fill in the survey for the second time. Main study data was collected in one day from the hospital using the printed surveys, and the online responses came in within 3 days. The total estimated number of surveys distributed (printed and online) was 600 surveys. The total responses were $338(56 \%)$. After discarding all missing data only $265(44 \%)$ responses were useable. (Table 1) shows descriptive statistics of respondents.

\begin{tabular}{|c|c|c|}
\hline \multicolumn{2}{|c|}{ Demographic Variables } & Data \\
\hline \multirow[t]{2}{*}{ Gender } & Male & $167(63.01 \%)$ \\
\hline & Female & $98(36.90 \%)$ \\
\hline \multirow{5}{*}{$\begin{array}{l}\text { Age } \\
(\text { Mean = 43.07, } \\
\text { S.D. = 6.92) }\end{array}$} & $<30$ & $40 \quad(15.09 \%)$ \\
\hline & $31-40$ & $93 \quad(35.09 \%)$ \\
\hline & $41-50$ & $77 \quad(29.05 \%)$ \\
\hline & $51-60$ & $31 \quad(11.70 \%)$ \\
\hline & $>60$ & $24 \quad(09.05 \%)$ \\
\hline \multirow{6}{*}{$\begin{array}{l}\text { Education } \\
\text { Level }\end{array}$} & Graduate & $46(17.35 \%)$ \\
\hline & $\begin{array}{l}\text { Under } \\
\text { Graduate }\end{array}$ & $60 \quad(22.64 \%)$ \\
\hline & $\begin{array}{l}\text { Associate } \\
\text { Degree }\end{array}$ & $24 \quad(09.05 \%)$ \\
\hline & $\begin{array}{l}\text { High } \\
\text { school }\end{array}$ & $82(30.94 \%)$ \\
\hline & $\begin{array}{l}\text { No High } \\
\text { School }\end{array}$ & $53 \quad(20.00 \%)$ \\
\hline & $\begin{array}{l}\text { No } \\
\text { Education }\end{array}$ & $0 \quad(0.00 \%)$ \\
\hline \multicolumn{2}{|l|}{ Total } & $265(100 \%)$ \\
\hline
\end{tabular}




\subsection{Instrument Validation}

To validate the measurement scale, the psychometric properties of the survey were assessed by applying Explanatory Factor Analysis (EFA) and Confirmatory Factor Analysis (CFA) using MPlus 7.1. Cronbach's $\alpha$ was computed using SPSS 20. After the pilot data was collected, we refined the items to keep only those with statistical significant loading larger of (0.7). Cronbach's $\alpha$ reliability tests for all constructs exceeded (0.8) [9]. After data was collected for the main study, CFA analysis was conducted one more time, and again all items had significant loadings greater than (0.7) except for the dichotomous factor indicator Loss Aversion within Perceived Value. It had a negative loading with no statistical significance $(\mathrm{p}=0.23>0.05)$, so Loss Aversion items were dropped from the scale. All constructs of the research model had Cronbach's $\alpha$ values exceeding (0.8). The CFA analysis provided strong support for our measurement model, which suggested that the items under each of the constructs were adequately measuring the constructs.

\section{Results}

The research model was tested by applying Structural Equation Modeling (SEM) using Mplus version 7.1. We applied the maximum likelihood estimator with robust standard errors (MLR). Because the model is not saturated (i.e., not all possible regression paths were included) we evaluated the model fit indicators and had no issues with fitness of the model. Following Bollen's [29] suggestions on evaluating Chi-Sqaure (X2), we calculated the Normed $\mathrm{X} 2(\mathrm{NC}=4.23)$. It is suggested that $\mathrm{NC}$ value between $(2.0$ and 6.0$)$ indicates reasonable fit. $\mathrm{CFI}$ is $(0.912)$ which conforms to the rule of thumb that values greater than roughly (.90) may indicate reasonably good fit of the researcher's model [31]. The Root Mean Square Error of Approximation (RMSEA) is (0.014). According to the rules of thumb by [35] RMSEA value between (0.05) and (0.08) suggest reasonable error of approximation. The standardized path coefficients and its level of significance are depicted in (Figure 2).

The research model explained $(65 \%)$ of the variance in the dependent variable Intention to Use PPS. Examining individual path coefficients, we find that majority of the initial hypotheses have been supported. Six of the nine hypothesized paths in the research model were statically significant. The directionality of each significant path (positive or negative) was also as hypothesized, providing overall support to our research model.

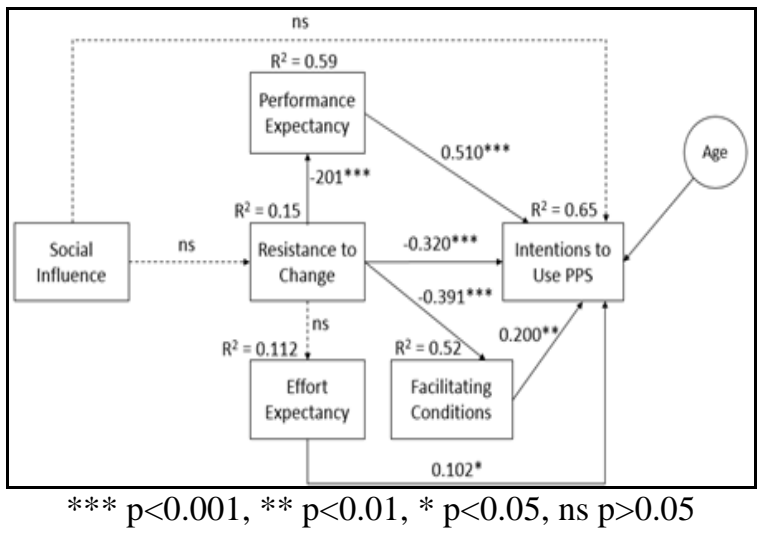

Figure 2: SEM Analysis of Research Model

Resistance to Change has predicated negatively all of Performance Expectancy, Facilitating Conditions, and Intentions to Use PPS. This indicates support to the dual factor model by confirming that the inhibitor to PPS usage (Resistance to Change) has negative influence on enablers to PPS usage (Performance Expectancy, Facilitating Conditions, and Intentions to Use). However, Resistance to Change had no significant effect on Effort Expectancy. This indicates that there is no influence of patients' resistance behaviors on their perceptions of levels of effort required (for example: levels of ease of use). So patients who are resisting the change to the new PPS may still be considering the system as "easy to use", however their decision to resist the system has no influence on their perceptions. These findings confirmed that Resistance to Change does indeed have a biasing effect on patients' perceptions of PPS Performance Expectancy and Facilitating Conditions, however the degree to this biasing may depend on the enabler perceptions that is being evaluated. The results indicate that Resistance to Change biases patients' perceptions of PPS's Facilitating Conditions more than Performance Expectancy. Similarly, findings show that some enablers and/or inhibitors may have less predicting power on usage intentions. For example, Performance Expectancy had a significant effect on use intentions $(\mathrm{p}<0.01)$ while Effort Expectancy had marginally significant effect on Intentions to Use PPS ( $\mathrm{p}<0.10)$.

Another interesting result is that all of Performance Expectancy, Effort Expectancy, and Facilitating Conditions had influenced patients' Intentions to Use PPS. According to (Venkatesh et al, 2003), prior research generally found that Facilitating Conditions have nonsignificant effect on Intentions to Use when Effort Expectancy constructs are accounted for in the 
model. One plausible reason for this finding is the context of the study. The compatibility of the PPS with patients' devices, and patients' sense of control over the new system are all playing major roles influencing their use intentions. These constructs are different when conducting studies on employees who use identical devices to accomplish similar tasks and share the same level of control over the technology they are using.

The results show that Social influence had no significant effect on Intentions to Use PPS, as well as Resistance to Change. This again may be explained by the context of the study. Patients tend to use the PPS alone with no communication with other patients about the system. Partly because patients normally do not have links of communication with one another. Also, because of privacy concerns, patients might not talk to others about the PPS to avoid discussions around their health issues. Thus, there is a lack of significant social influence being accounted for between patients.

Age was the only control variable that had significant effect on both the outcome variable Intentions to Use PPS - as well as the Resistance to Change construct. Educational level and sex had no significant effects.

Overall, our findings supported the initial expectation that patients' Intentions to Use PPS is predicted by both enablers (e.g., Performance Expectancy) and inhibitors (e.g., Resistance to Change) perceptions.

\section{Limitations}

This work has some limitations. First, inhibitors in this study were limited to Resistance to Change from the URM. Also, enablers were limited to the variables captured in the UTAUT. Future research is encouraged to include other enablers and/or inhibitors of usage that were not included in this Study. For example, perceived threat [2] as an inhibitor or enjoyment/satisfaction [7] as an enabler. Second, this study was conducted using specific sample (patients). This may limit the generalizability of its findings. We encourage researchers to replicate similar studies in different contexts with adverse sampling to make the work more generalizable. Third, because our data was collected from a single source, validation concerns may arise. Future research can apply a longitudinal study or collect data from multiple sources to validate the findings. Finally, we did not find social influence effects on use intentions nor resistance to change. We encourage future research to consider different types of social influence when testing its effects.

\section{Implications}

\subsection{For Research}

This work has a number of contributions to the IS research. First, this is one of the earliest studies that includes patients' perceptions of HIT. Prior IS research has focused mainly on HIT from the healthcare providers' perspective. Today's technology advancements are allowing patients to become major stakeholders of using HIT such as PPS, Self-monitoring devices, and telemedicine applications. Starting a stream of research that focuses on patients is a major advancement for the IS research on HIT. Second, this work provides empirical testing of URM's resistance to change in a different context which helps in making the URM more generalizable and opens the door for potential applications of the URM in a wide range of disciplines. Third, this is one of the fewest papers to test UTAUT on a technology that involves voluntary usage. Because of the wide spread of technology applications, hedonic and voluntary types of usage are becoming more popular and are shaping new ways of communication that leads to interesting research questions. Although UTAUT includes Voluntariness of Use as a moderator between Social Influence and Behavioral Intentions, but providing evidence that the UTAUT, as a whole, managed to explain voluntary usage will encourage researchers to build on these findings and provide more advancement to this area of research. Fourth, this work provides findings from an individual level. Most of prior studies have tested HIT resistance using group or organizational levels [5]. Thus, this work is enriching the IS literature by having findings from the novel sampling of individual patients. Finally, findings of this study posited that Facilitating Conditions can have positive effect on Intentions to Use while still accounting for the direct effects of Effort Expectancy and Performance Expectancy. This provides solid grounds for future research to hypothesis the effects of important Facilitating Conditions, such as compatibility, without the need to control for other important predictors.

\subsection{For Practice}

This work has also a number of important implications to practice. First, providing a better understanding of technology resistance in general and HIT resistance in particular would help decision makers be able to take necessary actions that can intervene and prevent system failures caused by resistance only [23]. Second, because HIT designers 
normally focus on system features with limited considerations of users' opinions [2], providing a better understanding of patients' resistance towards PPS may help design systems that are acceptable to the average user and still remain functionally good. Providing insights about how patients react towards the PPS helps system designers build new systems and/or update existing systems and increase adoption rates [16]. Third, because age was the only control variable that had significant effect on both Intentions to Use PPS and Resistance to Change, this sheds light on the possibility of providing seniors with other means of communication with the hospital that may be more suitable to that particular population. Finally, this work provides findings of technology resistance from an individual level perspective, this will give better insights to people of interest such as project managers and system designers about how end-users react individually rather than inferring results from studies conducted to measure these behaviors at organizational or group levels.

\section{References}

[1] A. Bandura, "Social Foundations of Thought and Action: A Social Cognitive Theory", Prentice Hall, Englewood Cliffs, NJ, 1986.

[2] A. Bhattacherjee, and N. Hikmet, "Physicians' resistance toward healthcare information technology: a theoretical model and empirical test," European Journal of Information Systems, 16, 6, 2007, pp. 725-737.

[3] A. Weeger, H. Gewald, and L.J. Vriesman, "Do Risk Perceptions Influence Physician's Resistance to Use Electronic Medical Records? An Exploratory Research in German Hospitals," 2011, AMCIS.

[4] B. Inder, and T. O.'Brien, "The Endowment Effect and the Role of Uncertainty", Bulletin of Economic Research (55:3), 2003, pp.289-301.

[5] B. Samhan, and K.D. Joshi, "Resistance of Healthcare Information Technologies; Literature Review, Analysis, and Gaps", In System Sciences (HICSS), Kawai, HI, 2015 48th Hawaii International Conference on (pp. 2992-3001), IEEE.

[6] B. Tulu, R. BURKHARD, and T.A. Horan, "Continuing use of medical information systems by medical professionals: empirical evaluation of a work system model", Communications of the AIS 18(31), 2007, pp. 641-656.

[7] B.H. Wixom, and P.A. Todd, "A theoretical integration of user satisfaction and technology acceptance", Information systems research, 16 (1), 2005, pp. 85-102.
[8] C. Archer, "Technology's Impact on Organizational Changes", Demand Media, 2015. http://smallbusiness.chron.com/technologys-impactorganizational-changes-20377.html

[9] C. Fornell, and D.F. Larcker, "Structural equation models with unobservable variables and measurement error: Algebra and statistics", Journal of marketing research, 1981, pp. 382-388.

[10] D. Hillson, and R. Murray-Webster, "Understanding and Managing Risk Attitude", Gower, 2007.

[11] D. Kahneman, and A. Tversky, "Choices, Values, and Frames", American Psychologist 39 (4), 1984, pp.341-350.

[12] D. Kahneman, and D.T. Miller, "Norm theory: comparing reality to its alternatives", Psychological Review 93, 1986, pp. 136-153.

[13] D. Sirdeshmukh, J. Singh, and B. Sabol, "Consumer Trust, Value and Loyalty in Relational Exchange", Journal of Marketing (66:1), 2002, pp. 15-37.

[14] D. Whitten, and R.L. Wakefield, "Measuring Switching Costs in IT Outsourcing Services", Journal of Strategic Information Systems (15), 2006, pp. 219-248.

[15] D.R. Compeau, C.A. Higgins, and S. Huff, "Social Cognitive Theory and Individual Reactions to Computing Technology: A Longitudinal Study," MIS Quarterly (23:2), 1999, pp. 145- 158.

[16] E. Poon, D. Blumenthal, T. Jaggi, M. Honour, D.W. Bates, and R. Kaushal, "Overcoming barriers to adopting and implementing computerized physician order entry systems in U.S. hospitals", Health Affairs 23, 4, 2004, pp. $184-190$

[18] F.D. Davis, "Perceived Usefulness, Perceived Ease of Use, and User Acceptance of Information Technology", MIS Quarterly, 13, 3, 1989, pp. 319-340.

[19] G. Zaltman and R. Duncan, "Strategies for Planned Change. John Wiley and Sons, New York, NY, 1977.

[20] G.C. Moore, and I. Benbasat, "Development of an Instrument to Measure the Perceptions of Adopting an Information Technology Innovation," Information Systems Research (2:3), 1991, pp. 192-222.

[21] H.C. Kelman, "Compliance, identification, and internalization: three processes of attitude change", Journal of Conflict Resolution, 2, 1958, pp. 51-60.

[22] H.W. Kim, "The effects of switching costs on user resistance to enterprise systems implementation", Engineering Management, IEEE Transactions on, 58(3), 2011, pp. 471-482. 
[23] H.W. Kim, and A. Kankanhalli, "Investigating user resistance to information systems implementation: a status quo bias perspective," MIS quarterly, 33, 3, 2009, 567-582.

[24] I. Ajzen, "The Theory of Planned Behavior," Organizational Behavior and Human Decision Processes (50:2), 1991, pp. 179-211.

[26] J. Hartwick, and H. Barki, "Explaining the Role of User Participation in Information System Use", Management Science (40:4), 1994, pp. 40-465.

[27] K. Joshi, "A Model of User Perspective on Change: The Case of Information Systems Technology Implementation”, MIS Quarterly, 15, 2, 1991, pp. 229-242.

[28] K. Lewin, "Frontiers in group dynamics: Concept, method, and reality in social sciences, social equilibria, and social change", Human Relations 1, 1947, pp. 5-41.

[29] K.A. Bollen, "Structural equation models," Encyclopedia of biostatistics, 1998.

[30] L. Lapointe, and S. Rivard, "A Multiple Model of Resistance to Information Technology Implementation", MIS Quarterly, 29, 3, 2005, pp. 461-491.

[31] L.T. Hu, and P.M. Bentler, "Cutoff Criteria for Fit Indexes in Covariance Structure Analysis: Conventional Criteria versus New Alternatives," Structural Equation Modeling, 6 (1), 1999, pp. 1-55.

[32] M. Parthasarathy, and A. Bhattacherjee, "Understanding postadoption behavior in the context of online services", Information Systems Research, 9(4), 1998, 362-379.

[33] M. Sherif, "The psychology of social norm", NewYork: Harper, 1936.

[35] M.W. Browne, and R. Cudeck, "Alternative ways of assessing model fit", Sage Focus Editions, 154, (1993): 136-136.

[37] R.L. Thompson, C.A. Higgins, and J.M. Howell, "Personal Computing: Toward a Conceptual Model of Utilization,” MIS Quarterly (15:1), 1991, pp. 124-143.

[38] R.T. Cenfetelli, "Inhibitors and enablers and dual factor concepts in technology usage," Journal of the Association of Information Systems, 5, 11, 2004, pp. 472492.

[39] S. Gächter, E.J. Johnson, and A. Herrmann, "Individual-level loss aversion in riskless and risky choices", 2007.

[40] S.M. Campbell, T. Shield, A. Rogers, and L. Gask, "How do stakeholder groups vary in a Delphi technique about primary mental health care and what factors influence their ratings?" Quality and Safety in Health Care 13.6 (2004), pp. 428-434.

[42] T.A. Spil, R.W. Schuring, and M.B. Michel-Verkerke, "Electronic prescription system: do the professionals use it?" International Journal of Healthcare Technology and Management, 6, 1, 2004, pp. 32-55.

[44] V. Venkatesh, and S.A.Brown, "A longitudinal investigation of personal computers in homes: adoption determinants and emerging challenges. MIS Quarterly 25(1), 2001, 71-102.

[45] V. Venkatesh, M.G. Morris, G.B. Davis, and F.D. Davis, "User Acceptance of Information Technology: Toward A Unifying View," MIS Quarterly, 27, 3, 2003, pp. 425-478.

[46] W. Lewis, R. Agarwal, and V. Sambamurthy," Sources of influence on beliefs about information technology use: An empirical study of knowledge workers. MIS quarterly, 2003, pp. 657-678.

[47] W. Samuelson, and R. Zeckhauser, "Status quo bias in decision making," Journal of risk and uncertainty, 1(1), 1988, pp.7-59

[48] Y.L. Wu, Y.H. Tao, and P.C. Yang, "The use of unified theory of acceptance and use of technology to confer the behavioral model of $3 \mathrm{G}$ mobile telecommunication users", Journal of Statistics and Management Systems, 11(5), 2008, pp. 919-949.

[49] Y.S. Foon, and B.C.Y. Fah, "Internet banking adoption in Kuala Lumpur: an application of UTAUT model", International Journal of Business and Management, 6(4), 2011, 161.

[50] Ahmad, A., Teater P., Bentley T.D., Kuhen L., Kumar R.R., Thomas A., and Mekhijan H.S., "Key attributes of a successful physician order entry system implementation in a multi-hospital environment", Journal of American Medical Informatics Association 9, 1, (2002), pp. 16-24.

[51] Yoon, Youngohc, and Tor Guimaraes. "Assessing expert systems impact on users' jobs." Journal of Management Information Systems, 12, 1, (1995), pp. 225249.

[52] Burnham, T., Frels J., and Mahajan V., 2003. "Consumer switching costs: A typology, antecedents, and consequences," Journal of Academic Marketing Science, vol. 31, no. 2, pp. 109-203.

[53] Taylor, S., and Todd, P. A. "Assessing IT Usage: The Role of Prior Experience," MIS Quarterly (19:2), 1995a, pp. 561-570.

[54] Taylor, S., and Todd, P. A. "Understanding Information Technology Usage: A Test of Competing Models," ISR (6:4), 1995b, pp. 144-176. 